

\title{
Quantitative Design of a High Performance Permanent Magnet Vernier Generator
}

Jian Zhang, Abdelmounaim Tounzi, Phillipe Delarue, Francis Piriou, Vlasios Leontidis, Antoine Dazin, Guy Caignaert, Antoine Libaux

\section{- To cite this version:}

Jian Zhang, Abdelmounaim Tounzi, Phillipe Delarue, Francis Piriou, Vlasios Leontidis, et al.. Quantitative Design of a High Performance Permanent Magnet Vernier Generator. IEEE Transactions on Magnetics, 2017, 53 (11), 10.1109/TMAG.2017.2707802 . hal-02160329

\section{HAL Id: hal-02160329 \\ https://hal.science/hal-02160329}

Submitted on 19 Jun 2019

HAL is a multi-disciplinary open access archive for the deposit and dissemination of scientific research documents, whether they are published or not. The documents may come from teaching and research institutions in France or abroad, or from public or private research centers.
L'archive ouverte pluridisciplinaire HAL, est destinée au dépôt et à la diffusion de documents scientifiques de niveau recherche, publiés ou non, émanant des établissements d'enseignement et de recherche français ou étrangers, des laboratoires publics ou privés. 


\title{
Quantitative Design of a High Performance Permanent Magnet Vernier Generator
}

\author{
Jian Zhang ${ }^{1}$, Abdelmounaïm Tounzi ${ }^{1}$, Phillipe Delarue ${ }^{1}$, Francis Piriou ${ }^{1}$, Vlasios Leontidis ${ }^{2}$, Antoine Dazin ${ }^{2}$, \\ Guy Caignaert ${ }^{2}$, and Antoine Libaux ${ }^{3}$ \\ ${ }^{1}$ Université Lille 1, Bât. P2, 59655 Villeneuve d'Ascq, FRANCE \\ ${ }^{2}$ Ecole National Supérieure D’Arts et Métiers (ENSAM), 8 Boulevard Louis XIV, 59046 Lille, FRANCE \\ ${ }^{3}$ EDF Hydro-Engineering Centre, Savoie Technolac 73373 Le Bourget-du-Lac, FRANCE
}

\begin{abstract}
Permanent magnet vernier machines are becoming more and more attractive due to their high torque density and low-speed operating capabilities. This paper investigates the effects of the magnet thickness, magnet pole arc ratio and slot open ratio on the torque capacity. An analytical model is firstly presented. It is validated by comparing the results with Finite Elements Analysis (FEA) under the same hypothesis. A mono-objective optimization is then conducted on the basis of the analytical model coupled to genetic algorithm to reach the optimal values yielding the highest value of the torque. Finally, the influence of nonlinear magnetic material behavior on the optimal design is investigated through nonlinear FEA. The results are presented and discussed.
\end{abstract}

Index Terms-Permanent magnet vernier machine, optimization, nonlinear magnetic material behavior, high torque density.

\section{INTRODUCTION}

$\mathbf{P}$ ERMANENT Magnet Vernier Machines (PMVM) could be a useful solution for the applications with limited volume due to their capacity to provide high torque density at low speed while being a simple structure when compared with classical Permanent Magnet Synchronous Machines (PMSM) [1], [2]. Those merits lead they are very suitable for the direct drive system applications [3]. Several topologies of PMVM have been proposed and investigated to improve the torque density and power factor recently [4]-[7]. In the case of surface mounted permanent magnet structure, the study of the main characteristics of the machine can be conducted using analytical approach with the assumption of high magnetic material permeability. This approach has been used by previous works to deal with the quantification of the machine performances and also the optimization of some influential variables to enhance the performance of prototypes $[\overline{8}]-[10]$. However, as the energy conversion in these machines is based, among others, on the variable reluctance of the air gap due to the stator slots with a significant opening, the saturation effect is not really negligible even the magnetic airgap of such machine is relatively large. This iron material nonlinear effect makes the hypothesis of the analytical approach less valid and then the accuracy of the optimization results is questionable.

In order to highlight this fact, this paper explores the influence of the main important parameters, i.e. magnet pole arc ratio, slot open ratio and magnet thickness on the performance (torque density) using analytical model and FEA (linear and nonlinear material cases). The analytical model of an outer rotor structure PMVM, under the hypothesis of very high iron material permeability, is firstly presented to clearly exhibit the key parameters which affect its torque capability. In the second part, the designed prototype is presented and its performances are investigated using the introduced model. The results are then validated by comparing them with the ones given by FEA under the same assumption. As generally done, the analytical approach is used to conduct an optimization of the three key parameters by using genetic algorithm. Finally, based on the optimal results, comprehensive FEA simulations taken into account the real $\mathrm{B}(\mathrm{H})$ curve of the magnetic material are conducted in order to study the effect of nonlinear behavior on the machine torque capacity and the optimization result accuracy.

\section{ANALyticAl MODEL}

The electromagnetic energy conversion of a PMVM is based on the interaction of armature magnetic field with the one of the rotating magnets which is modulated by the air gap permeance due to the open stator slots. Therefore, a special relationship among the rotor PM pole pair number $p_{r}$, stator winding pole pair number $p_{s}$ and stator slots number $Z_{s}$ should be satisfied [2]:

$$
p_{r}=Z_{s} \pm p_{s}
$$

Within the classical hypothesis of a very high magnetic permeability of the iron, the magnetic energy is located in the air gap of the machine and can then be expressed using the Magneto-Motive Forces (MMF) and the air gap permeance.

The permanent magnet MMF can be expressed as:

$F_{p}(\theta, t)=\sum_{n=1,3,5, \ldots}^{\infty} \frac{4 B_{r} h_{m}}{\pi n \mu_{o} \mu_{r}} \sin \left(\frac{\pi}{2} n \beta_{p m}\right) \cos \left(n p_{r}\left(\theta-\omega_{m} t\right)\right)$

where $B_{r}$ is the magnet remanence; $h_{m}$ is the magnet thickness; $\beta_{p m}$ is the PM pole arc ratio; $\omega_{m}$ is the mechanical rotational speed. $\theta$ is the mechanical angle on the stator which equals to $\theta_{m}+\theta_{r}$ as shown in Fig.1. $\theta_{m}$ is the rotor position which equals to $\omega_{m} t ; \theta_{r}$ is the mechanical angle on the rotor. $\mu_{r}$ is the magnet relative permeability and $\mu_{o}$ is the permeability of vacuum. 




Fig. 1. Machine mechanical angle definition.

The stator winding MMF is:

$$
\begin{aligned}
F_{w}(\theta, t)= & \frac{3 \sqrt{2} N I}{p_{s} \pi}\left[\sum_{n=1,7,13, \ldots}^{\infty} \frac{k w_{n}}{n} \cos \left\{n p_{s} \theta-(\omega t-\alpha)\right\}\right. \\
& \left.+\sum_{n=5,11,17, \ldots}^{\infty} \frac{k w_{n}}{n} \cos \left\{n p_{s} \theta+(\omega t-\alpha)\right\}\right]
\end{aligned}
$$

where $N$ is the number of turns for one phase winding; $I$ is the effective current; $k w_{n}$ is the $n^{t h}$ harmonic winding factor; $\omega$ is the angular frequency of current; $\alpha$ is the phase initial angle which can influence the output torque.

As the magnets are mounted on the rotor surface, the variation of the air gap permeance is due to only the open stator slots. Its density is given by the following expression [11]:

$$
\Lambda(\theta)=\frac{\mu_{o}}{l_{g}+\frac{h_{m}}{\mu_{r}}+\delta_{s}(\theta)}
$$

where $l_{g}$ is the air gap length. $\delta_{s}(\theta)$ is the additional air gap length which is used to model the slotting effect and it can be expressed as follows:

$$
\delta_{s}(\theta) \approx a_{0}+\sum_{n=1}^{\infty} a_{n} \cos \left(n Z_{s} \theta\right)+\sum_{n=1}^{\infty} b_{n} \sin \left(n Z_{s} \theta\right)
$$

and

$$
\begin{gathered}
a_{0}=\frac{R_{s}\left(\pi k_{t}\right)^{2}}{6 Z_{s}} \\
a_{n}=-\frac{R_{s}}{2 Z_{s} n^{2}}\left[1+\cos \left(2 \pi n k_{t}\right)-\frac{1}{\pi n k_{t}} \sin \left(2 \pi n k_{t}\right)\right] \\
b_{n}=\frac{R_{s}}{2 Z_{s} n^{2}}\left[\frac{1}{\pi n k_{t}}\left(1-\cos \left(2 \pi n k_{t}\right)\right)-\sin \left(2 \pi n k_{t}\right)\right]
\end{gathered}
$$

where $R s$ is the stator bore radius and $k_{t}$ is the slot open ratio.

Then the air gap flux density is calculated as:

$$
B(\theta, t)=\left(F_{p}(\theta, t)+F_{w}(\theta, t)\right) \Lambda(\theta)
$$

From the field energy theory, the torque of the machine can be deduced by:

$$
T=\frac{d W}{d \theta_{m}}=L R_{s} \int_{0}^{2 \pi}\left\{\frac{\partial}{\partial \theta_{m}}\left(\frac{1}{2} \frac{B^{2}(\theta, t)}{\Lambda(\theta)}\right)\right\} d \theta
$$

where $L$ is the machine active length.

Based on physical considerations and the above equations, once the air gap mechanical length $l_{g}$ chosen with respect to mechanical constraints, the key structure parameters which



Fig. 2. No load flux distribution of one quarter of the designed generator.

influence the torque capability are $h_{m}, \beta_{p m}$ and $k_{t}$ for a machine with specific pole slot combination, magnet material and active volume.

\section{MODEL VALIDATION AND OPTIMIZATION}

A first prototype has been designed using analytical approach. The rated power is $45 \mathrm{~kW}$ at $50 \mathrm{rpm}$ and $36.6 \mathrm{~Hz}$ $\left(p_{r}=44, p_{s}=4\right.$ and $\left.Z_{s}=48\right)$. The magnet thickness, pole arc ratio and slot open ratio values have been fixed as $6 \mathrm{~mm}$, 0.7 and 0.5 respectively.

The performances of the designed prototype are firstly determined using the analytical model above and compared with the results given by finite element method under the same assumptions. Then, the analytical model is validated to optimize the three parameters $h_{m}, \beta_{p m}$ and $k_{t}$ by genetic algorithm.

A homemade 3D time stepping FEA code called code_Carmel is used to conduct the FEA. In the present work, a $2 \mathrm{D}$ vector potential formulation A has been used to carry out the calculations both in linear and nonlinear behavior of the magnetic material.

\section{A. Model validation}

By using the analytical model, the performances of the prototype are calculated in terms of magnetic field density and electromagnetic torque. These variables have also been determined using FEA with the assumption of a very high permeability of the magnetic material.

Fig 2 depicts the magnetic flux density distribution of one quarter of the designed generator. Due to the modulation of the PM flux by the stator slots, it clearly shows that it looks like just 4 pole pairs machine (in the stator) even if the rotor has 44 pole pairs.

Fig 3(a) presents the waveforms of the air gap flux density, with respects to the position, obtained both by analytical and FEA. This shows that the analytical approach is relatively accurate. The torque waveforms are also compared in Fig $3(\mathrm{~b})$ The analytical model results in more torque ripple and slightly lower average torque than FEA. However, the relative error of average torque between them is around $1 \%$ which is very small. The analytical approach can then be considered as valid and be used to conduct the optimization of the three key parameters. 




(a)



(b)

Fig. 3. FEA and analytical simulation comparison (Stars: FEA; Line: Analytical). (a) No load air gap flux density; (b)Torque.



(a)



(c)



(b)



(d)
Fig. 4. Optimization results. Evolution of (a) Torque; (b) Magnet thickness; (c) PM pole arc ratio; (d) Slot open ratio.

\section{B. Optimization}

A mono-objective optimization is implemented using genetic algorithm to maximize the torque capability with continuous variable ranges for $h_{m}, \beta_{p m}$ and $k_{t}$ from $1 \mathrm{~mm}$ to $10 \mathrm{~mm}, 0.1$ to 1 and 0.1 to 1 respectively. Also, the crossover and mutation probability are kept to 0.8 and 0.05 respectively. 400 generations, with popular size equals to 100 , have been tested and the optimization results are shown in Fig 4 . As large number of harmonics are taken into consideration, the total computation time is around 5 hours on a quad core PC. The results indicate that the maximum torque, $2628.2 \mathrm{~N} . \mathrm{m}$, can be achieved with $h_{m}=5.1 \mathrm{~mm}, \beta_{p m}=1$ and $k_{t}=0.543$. Contrary to what it could be expected, the results show that larger magnet thickness does not increase the machine torque while lager pole arc ratio can lead to this goal.



Fig. 5. Waveform of the average torque as a function of magnet thickness (pole arc ratio 1 , slot open ratio 0.55 )

\section{NONLINEAR MATERIAL INFLUENCE}

To investigate the sensibility of the optimization results and to quantify the impact of the nonlinear behavior of the magnetic material on these values, calculations are carried out using FEA approach while considering the $\mathrm{B}(\mathrm{H})$ curve of M400-50A steel for the magnetic material.

To do this, three calculation sets are performed. In each case, two of the three parameters $\left(h_{m}, \beta_{p m}\right.$ and $\left.k_{t}\right)$ are kept at their optimal values while the third one is varied with constant steps. For all cases, initial phase angle $\alpha$ of the armature current is chosen to achieve maximum torque.

Fig 5 shows the variation of the average torque according to the magnet thickness. It can be seen that analytical results match well the one obtained by FEA under the hypothesis of linear magnetic material. However, there is a significant difference when accounting for $\mathrm{B}(\mathrm{H})$ curve in FEA in terms of torque capability but also in terms of evolution shape. On one hand, the curve is more flat and, on the other hand, the optimal magnet thickness is higher $(7 \mathrm{~mm}$ instead of $5.1 \mathrm{~mm}$ in the case of analytical approach). This can be explained by the fact that as the saturation effect is taken into account, a part of the magnet MMF is dissipated in the magnetic material. Therefore, to reach the same magnetic flux density in the air gap, the thickness of the magnet is unavoidably increased.

Fig 6 depicts the torque capability with respects to the PM pole arc ratio. As expected and also found in other work [10], even if the ends of the pole magnets are short-circuited, the pole arc ratio equals to one constitutes the optimal value given either by analytical approach and FEA. However, for such ratio, the maximal average torque is rather lower when the non-linearity of the material is considered.

Finally, the values of the average torque given by the three approaches with respects to the slot open ratio are presented in Fig 7. As it can be seen, the trends of the waveforms are similar. However, in addition to the significant decrease in torque magnitude, taking into account the nonlinearity of materials also induces an optimal value of the slot open ratio that is slightly different from the one by using analytical model. Thus, in the latter case, as by using the FEA with a linear $\mathrm{B}(\mathrm{H})$ curve, the maximum torque corresponds to $k t=0.55$ while the value given in nonlinear magnetic material condition is $k t=0.5$. 


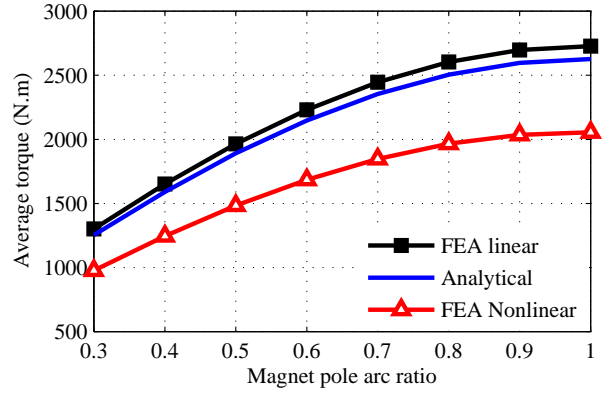

Fig. 6. Waveform of the average torque according to PM pole arc ratio (magnet thickness $5 \mathrm{~mm}$, slot open ratio 0.55)



Fig. 7. Waveforms of the average torque with respects to slot open ratio (magnet thickness $5 \mathrm{~mm}, \mathrm{PM}$ pole arc ratio 1)

The above results show that the nonlinear behavior of the magnetic material is a very important task and it should be carefully dealt with in PMVM. In this structure, the magnets are surface mounted as in classical PMSM. However, as the MMF of the magnets has to be modulated by the air gap permeance to reach an electromagnetic energy conversion, the inner surface of the stator must be toothed with large open slots. This induces a saturation effect whose impact is more important than in the case of PMSM. Thus, compared to the analytical approach, the machine average torque is smaller. The results from an optimization procedure neglecting the nonlinear behavior of the material should be taken with care.

In the FEA simulations, the interaction among the three parameters has not been included but it will not significantly affect the results. Rigorously, the optimization of a PMVM should be conducted using FEA while the real $\mathrm{B}(\mathrm{H})$ curve of the magnetic material is accounted for. However, as it is well known, this takes very long calculation times. An alternative procedure would be the use of an analytical model to achieve a first machine geometry design and fast optimization. Then, in a second step, a second optimization, using nonlinear numerical model, should be performed but in a more limited research space just around the optimal values from the first optimization. This obviously does not limit the calculation time inherent to the FEA. But it will definitely lead to accelerating the optimization process. This would be adequately complemented by the use of procedures such as Kriging optimization or factorial experiment.

\section{CONCLUSION}

In this work, the analytical model of PMVM has been presented and used to calculate the machine torque. Once validated by comparing its results with the ones given by FEA under the same hypothesis of very high magnetic material permeability, it has been used to reach the optimal values of three key parameters of the machine, i.e. magnet thickness, PM pole arc ratio and slot open ratio.

The optimization results show that the machine torque can be significantly improved. However, a second study using FEA while taking account for the nonlinear behavior of the magnetic material show that the latter has a non-negligible effect on the results in terms of torque magnitude but also in terms of the optimal values of the optimized variables. Therefore, contrary to what is commonly admitted, the analytical model is not sufficient to conduct an efficient optimization of such machine. However, as proposed, it can be used to achieve a first optimization with little calculation time which permits to delimit the research space of the variables to be optimized. Then, a second optimization can be carried out with the nonlinear numerical model in order to refine the optimal values with a limited time calculation.

\section{ACKNOWLEDGMENT}

The authors would like to thank the Region Hauts de France, Electricité de France (EDF) and Voies Navigables de France (VNF) who financially supported this project.

\section{REFERENCES}

[1] D. Li, R. Qu, J. Li, L. Xiao, L. Wu and W. Xu, "Analysis of Torque Capability and Quality in Vernier Permanent-Magnet Machines," IEEE Trans. Ind. Appl., vol. 52, no. 1, pp. 125-135, Jan./Feb. 2016

[2] A. Toba and T. A. Lipo, "Generic torque-maximizing design methodology of surface permanent-magnet Vernier machine," IEEE Trans. Ind. Appl., vol. 36 , no. 6, pp. 1539-1546, Nov./Dec. 2000

[3] L. Xu, G. Liu, W. Zhao, X. Yang and R. Cheng, "Hybrid Stator Design of Fault-Tolerant Permanent-Magnet Vernier Machines for Direct-Drive Applications," IEEE Trans. Ind. Electron., vol. 64, no. 1, pp. 179-190, Jan. 2017

[4] L. Xu, G. Liu, W. Zhao, J. Ji and X. Fan, "High-Performance Fault Tolerant Halbach Permanent Magnet Vernier Machines for Safety-Critical Applications," IEEE Trans. Magn., vol. 52, no. 7, July 2016

[5] D. Li, R. Qu, and T .Lipo, "High power factor vernier permanent magnet machines," IEEE Trans. Ind. Appl., vol. 50, no. 6, pp. 3664- 3674, Dec. 2014

[6] Y. Gao, R. Qu, D. Li, H. Fang, J. Li, "A Novel Dual-Stator Vernier Permanent Magnet Machine," IEEE Trans. Magn., vol.PP, no.99, 2017

[7] T. W. Ching, K. T. Chau and W. Li, "Power Factor Improvement of a Linear Vernier Permanent-Magnet Machine Using Auxiliary DC Field Excitation,” IEEE Trans. Magn., vol. 52, no. 7, pp. 1-4, July 2016.

[8] B. Kim and T. Lipo, "Operation and design principles of a PM vernier motor," IEEE Trans. Ind. Appl., vol. 50, no. 6, pp. 3656-3663, Dec.2014

[9] G. Liu, S. Jiang, W. Zhao and Q. Chen, "A New Modeling Approach for Permanent Magnet Vernier Machine With Modulation Effect Consideration," IEEE Trans. Magn., vol. 53, no. 1, pp. 1-12, Jan. 2017.

[10] L. Wu, R. Qu, D. Li and Y. Gao, "Influence of Pole Ratio and Winding Pole Numbers on Performance and Optimal Design Parameters of Surface Permanent-Magnet Vernier Machines," IEEE Trans. Ind. Appl., vol. 51, no. 5, pp. 3707-3715, Sept.-Oct. 2015

[11] B. Gaussens, E. Hoang, O. de la Barriere, J. Saint-Michel, M. Lecrivain and M. Gabsi, "Analytical Approach for Air-Gap Modeling of FieldExcited Flux-Switching Machine: No-Load Operation," IEEE Trans. Magn., vol. 48, no. 9, pp. 2505-2517, Sept. 2012. 